\title{
Decision support on risk based land management and sustainable rehabilitation of radioactive contaminated territories
}

\author{
B. Yatsalo and P. Bardos ${ }^{1}$ \\ Obninsk Institute of Nuclear Power Engineering, Kaluga Region, Obninsk, Russia \\ ${ }_{1}^{3}$ Environmental Technology Ltd., U.K.
}

\begin{abstract}
The general questions of decision-making support on Risk Based Land Management (RBLM), including key factors and components, range of existing decision support and analytical tools and techniques are considered. The characteristics and possibilities of the applied Decision Support System PRANA as a tool for decision support on RBLM and sustainable rehabilitation of radioactive contaminated territories are described.
\end{abstract}

\section{DECISION-MAKING SUPPORT}

The topic of contaminated land has been an increasingly important one in many areas of policy, research and practice both within different countries and at international level [1,2].

Land is considered contaminated when there is a risk of unacceptable harm from pollutant during its present or intended use (see Figure 1). In scientific and technical terms contaminated land can impact on

- human health,

- quality of surface and groundwater,

- nature and viability of ecosystems,

- buildings and other materials and artefacts within the ground,

- and the visual amenity of an area.

Decision-making, in the face of uncertainty and multiple and often conflicting objectives, is a vital and challenging role in contaminated land management. Finding sustainable technical solutions for contaminated problems is dependent on a range of parallel considerations. Decisions about which risk management option(s) are most appropriate for a particular site needs to be considered in a holistic manner. Key factors in decision making include [3, 4]:

- driving forces for the remediation project,

- risk management,

- sustainable development,

- stakeholders' viewpoints,

- cost effectiveness, and

- technical feasibility / suitability.

Although each environmental remediation problem is unique and will require a site-specific analysis, many of the key decisions are similar in structure. The large number of contaminated land problems with similar characteristics has led many countries to attempt to develop tools (DST) that support the wide range of decisions related to contaminated land management and re-use using standard approaches $[3,4]$. 
Decision Support can be defined as the assistance for, and substantiation and corroboration of, an act or result of deciding. Typically this deciding will be a determination of optimal or best approach. The decision-making process for any problem usually encompasses:

- an identification phase of the problem(s),

- a development phase in which possible solutions/scenarios are identified and developed,

- a selection phase (a choice of the solution(s) to be implemented).

Decision support integrates specific information about a site and general information such as legislation, guidelines and know-how, to produce decision-making knowledge in a way that is transparent, consistent and reproducible.

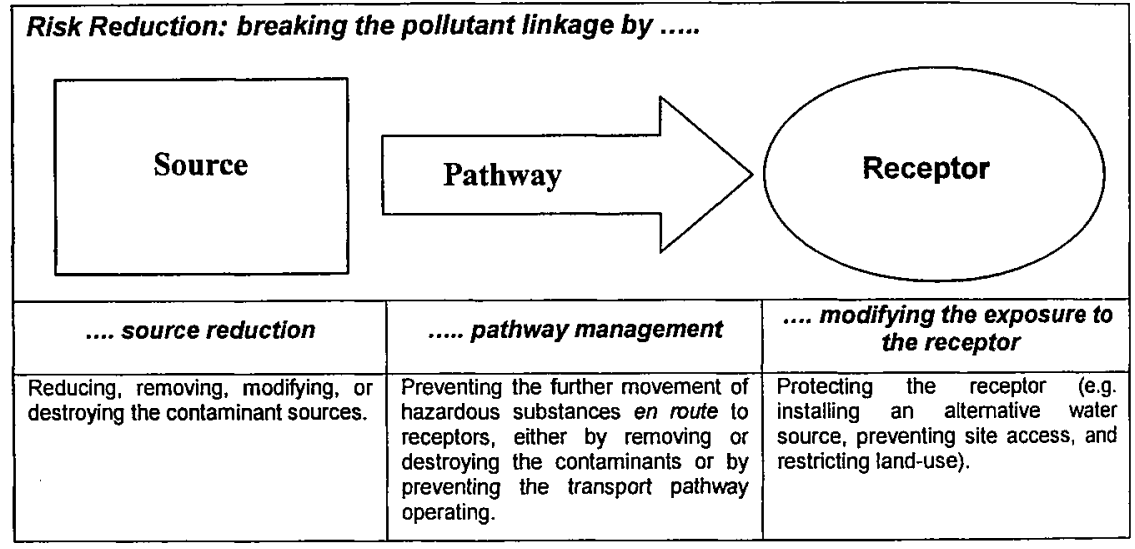

Figure 1 Risk Management and Risk Reduction [3]

Several 'layers' of decision support can be distinguished:

-the input information,

- tools to assist particular decision-making issues, and

- the overall system in which decision making is applied.

The wide range of existing DS varies from simple diagrams derived from standards or regulations, to software based systems. Applications have been developed for contaminated site management, involving the characterisation of contamination, risk assessment phases, risk management, aftercare and monitoring. In the context of contaminated land management a simple framework to classify DSTs based on four types of category may be used [4,5]:

1. Functional application. The functional application to contaminated land management describes whether the decision support is for risk management, remediation, monitoring and aftercare, sustainable development etc. This deals with the issues that must be addressed to support the overarching decision. In practice, a number of DSTs address multiple decision criteria.

2. Analyses used. Several different techniques can be employed to assist environmental decision-making. In practice, many decision support tools use several of these techniques, or mixtures of different parts of them. For example, software tools might combine risk assessment and cost-benefit analysis techniques to generate risk maps, cost comparisons between remedial options and other decision information. 
3. Decision making role. The decision making role describes the type of decision making being supported, e.g. for managing a single site, or for prioritising a number of sites. This deals with the overarching decision being made at the site.

4. Nature of the product. The nature of the product describes whether the tool is written guidance; a "map" of some sort, a series of procedures or a software based system. (with different levels of complexity, including problem specific computer modules/systems, GIS).

The principal analytical tools and techniques so far used to support environmental decision making for contaminated land management are:

- Environmental Risk Assessment (ERA)

- Multi-Criteria Analysis (MCA)

- Multi-attribute techniques (MAT)

- Cost-Benefit Analysis (CBA)

- Cost Effectiveness Analysis (CEA)

- Life Cycle Assessment (LCA)

A key component of many DSSs for contaminated land risk management are electronic maps and elements of Geographic Information System (GIS). These tools are not only suitable for presentation of spatial input/output information, but also are irreplaceable means for setting and assessing different scenarios, where spatial structure, geometry of polygons and their positional relationship play a key role (spatial analysis, class of transportation problems, analysing scenarios with consideration of distance and area functions when assessing risk values, etc.).

Globally, a number of DSSs are available to identify remediation approaches for particular contaminated site problems, and using site specific information $[1-3,5,6,9]$. These tools tend to be based mainly on risk management performance and cost considerations. However, some tools are under development to take into account broader constraints (broader economic and environmental impacts, administrative issues, social impacts and risk perception). Nevertheless, the practical use of DSSs in contaminated land risk management planning is surprisingly limited.

\section{RBLM ON THE BASIS OF THE PRANA DSS}

Geographic Information System (GIS) PRANA is a Decision Support System for countermeasure analysis and rehabilitation of radioactive contaminated territories in the long-term period of liquidating the consequences of a nuclear accident. Conceptual requirements to GIS-DSSs meet all the main demands to DSSs for practical use, research and training on rehabilitation of contaminated territories that were elaborated in contacts with interested parties (Ministry of Agriculture, Minatom, Ministry of Health and Administration of Bryansk region). Realisation of the planned requirements and tasks are achieved through developing several GIS-DSSs - family of PRANA systems, each of them is intended for analysis of specific range of problems:

- GIS-DSS for practical use (with introduction at appropriate Ministries and Centres for decisionmaking support on rehabilitation of radioactive contaminated territories of Bryansk region on regional and local levels);

- GIS-DSS for research and for scientific and practical estimations;

- GIS-DSS for training and education;

- elements of distributed system and remote access to components of GIS-DSS.

The following sections, which have been realised in accordance with the chosen level of the system, represent in the aggregate a basis of each GIS-DSS indicated above $[6,9]$ : 
- libraries of electronic maps (including different layers of vector maps of landuse for territories under consideration);

- databases (radioecological, economic, demographic and other monitoring data), including detailed attributive information for each polygon of landuse map;

- spatial analysis of various data from databases, including spatial analysis of radioactive contamination;

- models for various aspects of risk analysis;

- protective measures (countermeasures, CMs) in the long-term period after an accident and estimation of the results of their implementation;

- multi-criteria assessment of CMs effectiveness and optimisation of the countermeasure structure $[7]$

- implementation of radiological protection principles (as well as existing requirements of international and national standards and legal regulations) [8];

- decision-making support on protection of the population and rehabilitation of radioactive contaminated territories both on local and regional/district levels (from separate settlement/field up to group of settlements/farms and region as a whole) $[6,7]$.

The following 'risk indices' are considered within decision-making on the basis of PRANA DSS:

- surface density contamination of territory with radionuclides $\left({ }^{137} \mathrm{Cs},{ }^{90} \mathrm{Sr}\right.$ and, for some areas, ${ }^{239+240} \mathrm{Pu}$ );

- contamination of agricultural production (plant growing and animal husbandry, including farm and private production);

- external and internal doses to the local population (for different age and occupational groups of each settlement for region under consideration)

- radiological risks caused by irradiation of the population;

- expenses associated with necessity of CMs implementation and rehabilitation procedures along with corresponding criteria of effectiveness.

At present PRANA GIS-DSSs for practical use and research comprise vector electronic maps of landuse (along with associated maps of contamination, soil types, etc.) and corresponding attributive information for five the most contaminated districts of Bryansk region: Novozybkov, Klintsy, Gordeevsky, Krasnogorsky and Zlynkovsky districts (more than 20000 polygons of vector electronic maps). Possibilities of GIS are actively used when presenting/searching source data and modelled values, forming scenarios for subsequent analysis, agricultural produce and external/internal dose assessing, ranking territories (farms) and polygons (settlements, fields), etc.

Realisation of radiological protection principles with corresponding constraints includes solving the following tasks within the work package on 'optimisation of CMs structure and RBLM'.

1) Analysis of effectiveness (for a given set of criteria) for each $\mathrm{CM}$ for various radiological, ecological, socio-economic and other conditions $[6,7]$.

2) (Direct task) Determination of the specific territories/objects (fields, settlements, farms) for a given region where CMs can be or should be implemented according to the strategy of rehabilitation; determination of corresponding means (cost, materials, etc.); assessment of effectiveness (for the chosen criteria) for each CM and system of CMs for real/specific conditions; analysis of alternatives [6,9].

This is so-called 'task without restrictions'. When solving tasks of such a class expert(s) choose objects for analysis (polygons), set of available CMs, criteria as well as other characteristics and parameters, which form the scenarios for subsequent investigation. Output values of criteria are analysed. Expert can form different scenarios (polygons and CMs) and receive corresponding values of the given criteria. For solving such a task ranking algorithms (ranking polygons, territories) are used actively.

After detailed analysis of different scenarios of CMs implementation experts can recommend for realisation 'the best one' with their point of view, that corresponds to the current radiological, economic and other conditions. 
3) (Inverse task) Taking into account the set of available CMs and objects of possible implementation of CMs, experts have to chose such their subset, that realisation of the chosen CMs on chosen objects/polygons provides an optimal value for a given criteria and satisfies conditions of financial and other (ecological, economic, etc.) restrictions.

The interface of PRANA allows using possibilities of modules developed for visualisation of source data, carrying out different assessments and their analysis (zoning and ranking of lands, settlements and farms according to a criterion chosen using source data and modelled values), formation of various scenarios for analysis, the estimation of different strategies of CMs implementation and land use along with subsequent decision making on optimisation of radiological protection and RBLM of radioactive contaminated territories. Presentation of output information comprises all the results on estimations of risk values (production contamination, structure of population doses, costs and countermeasure effectiveness) as well as integration of estimates from initial polygon (field, settlement) up to the farm or group of farms chosen and district/region as a whole (see more detailed description in [3]). Assessments of all the main 'risk indices' for specific conditions of Bryansk region/farms and settlements will be published in a series of publications (under preparation).

Risk Based Land Management for radioactive contaminated territories is primarily a framework for integration of the following key stages:

- estimation of the main scenarios/variants of rehabilitation (including the choice of sites/territory for remediation along with site-specific CMs and time of their implementation) with consideration of all the main aspects of risk(s) and possible longer term impacts of particular choices;

- the choice of solution(s): this requires an assessment of overall benefits, costs and environmental side effects, value and circumstances of the land, community and stakeholders views and other issues taking into account values of quantitative and qualitative criteria, principles of radiological protection and existing standards and regulatory documents;

- realisations of the solution(s), taking into account site-specific economic, ecological and other characteristics and requirements.

Contaminated territory management is a set of activities involving decisions about assessment, remediation, land use restrictions, monitoring, spatial planning, aftercare and other issues. In the context of RBLM, it is a much broader activity than 'choosing a remediation technique'. It includes all the aspects of developing and implementing a sustainable approach taking into account estimates of risks along with other ecological, economic and social factors.

Implementation of PRANA DSS for RBLM of radioactive contaminated territories covers all the main aspects of assessing 'risk indices', except for complex economic appraisal, social and psychological and some other risks. At present a work package on implementation of GIS-DSS for sustainable appraisal and rehabilitation/development is under elaboration. This work package includes implementation not only existing landuse map and PRANA possibilities, but also use of detailed map of site/settlement and surroundings for RBLM on different levels (regional, farm and settlement levels).

Such a work package along with radiological, ecological, economic and social and psychological ones form a framework on "Risk Based Land Management and Sustainable Rehabilitation and Development of Radioactive Contaminated Territories" that is under development.

Thus, PRANA DSS for practical needs and research is one of the up-to-date tools for risk based land management and for primary evaluation of some aspects within the problem of sustainable rehabilitation of radioactive contaminated territories. 
The work on development of PRANA DSSs for practical needs and research is a part of R\&D carried out by Russian scientists (RRC KI, OINPE, RRC IB, IRH and BCAHR) within the ISTC project \#1224 and (in the part of spatial analysis) within the INTAS project \#31726.

\section{References}

1. Ferguson, C., Darmendrail, D., Freier, K., Jensen, B.K., Jensen, J., Kasamas, H., Urzelai, A. \& Vegter, J., eds. (1998) Risk Assessment for Contaminated Sites in Europe. Vol. 1, Scientific Basis. LQM Press, Nottingham, ISBN 0953309010

2. Ferguson C. C. and Kasamas, H. (1999) Risk Assessment for Contaminated Sites in Europe. Volume 2. Policy Frameworks. Report of CARACAS Project: Concerted Action on Risk Assessment for Contaminated Sites in the European Union. LQM Press, Nottingham. ISBN 0953309010.

3. Nathanail, J. Bardos, P. \& Nathanail, P. (2001) Contaminated Land Management Ready Reference Guide. EPP Publications/ Land Quality Press (In press). Available from: EPP Publications, 52 Kings Road, Richmond, Surrey TW10 6EP, UK. E-mail: enquiries@epppublications.com

4.R.P.Bardos, C.Mariotti, and S.N.Nortcliff A Framework and Categorisation of Decision Support Tools Used in Contaminated Land Management Across Europe. - Proc. of the Intern. Confer, ConSoil-2000, Leipzig, Germany, Sept. 18-22, 2000, p.169-170.

5. Bardos, R.P., Lewis, A, Nortcliff., S., Mariotti, C., Marot, F, and Sullivan, T. (In Preparation) Review of Decision Support Tools and their use in Europe: Report of CLARINET Working Group 2. Available from www.clarinet.at (from October 2001)

6.B.Yatsalo, O.Mirzeabassov, I.Okhrimenko, I.Pichugina and B.Lisyansky PRANA: Gieoinformation Decision Support System for Protection and Rehabilitation of Agrosphere after Nuclear Accident.J. of Hazardous Materials. 1998, v.61(1-3), p.381-384.

7. B.I.Yatsalo, P. Hedemann Jensen and R.M.Alexakhin Methodological Approaches to Analysis of Agricultural Countermeasures on Radioactive Contaminated Areas: Estimation of Effectiveness and Comparison of Different Alternatives. Radiat. Prot. Dosim. 1997, v.74, No 1/2, p.55-61.

8. P.Hedemann Jensen and B.I.Yatsalo Methodology for Determining Action Levels for Clean-up of Contaminated Urban and Agricultural Environments. - Health Phys. 75(2):120-129; 1998.

9. B.Yatsalo, O.Mirzeabassov, I.Okhrimenko, I.Pichugina, et al. Geographic Information Decision Support System for Rehabilitation of Radioactive Contaminated Territories. - Proc. of the Intern. Confer. ConSoil-2000, Leipzig, Germany, Sept. 18-22, 2000, p.433-441. 